\title{
Should Nano-Particles be Weighed or Counted? Technical Considerations to In Vitro Testing Originated from Corpuscular Nature of Nano-Particles
}

\author{
Wojciech Kałas $^{1}$ (D)
}

Received: 22 February 2021 / Accepted: 26 June 2021 / Published online: 3 August 2021

(c) The Author(s) 2021

\begin{abstract}
The abundance of nanoparticles introduced to household products created the great expectations towards the application of nanotechnology in biology and medicine. That calls for cost-effective preliminary assessment of its cytotoxicity and biological activity. There are many attempts for creating proper guidance and standards for performing studies regarding nanoparticles. But still some important aspects crucial for in vitro testing of nanomaterials need more attention. Particulate nature is an obvious and widely unappreciated property of nanoparticles. In the context of in vitro studies, this property is critical, and it should be, but rarely is, considered when designing, performing, describing or interpreting the experiments involving the solid nanoparticles. First, we should be aware of relatively small and limited number of nanoparticles in the experimental setup. Even crude estimation of its number will be useful for proper interpretation of results. Second, we should not presume even distribution of particles in the solution, moreover we should expect that sedimentation and aggregation play an important role in interactions of nanoparticles with cells. In that case, expressing the dose in mass/volume units may lead as astray. Finally, the relation of size, weight, and number of nanoparticles makes comparisons of activity of nanoparticles of different sizes very complex. Estimations of number of nanoparticles in the dose should be an integral part of experiment design, its validation and interpretation.
\end{abstract}

Keywords Nanoparticles $\cdot$ Dosing $\cdot$ Nano-compounds $\cdot$ In vitro $\cdot$ Cytotoxicity $\cdot$ Particulate matter $\cdot$ Inorganic nanoparticles

\section{Introduction}

We are living at the dawn of the nanotechnology revolution. The number of new nanomaterials designed for professional and household applications grows rapidly every year (Hobson et al. 2016). Nanoparticles have relatively large area comparing to its overall mass. Thus, most of the atoms of small, few nanometer size nanoparticle are located on the surface (Naito et al. 2018). This is a main reason of the unique properties of nanomaterials comparing to its similar micro and macro counterparts.

The great variety of nanoparticles are embedded in household products. Its presence rises our interest about the

Wojciech Kałas

wojciech.kalas@hirszfeld.pl

$1 \quad$ Hirszfeld Institute of Immunology and Experimental Therapy, Polish Academy of Sciences, Rudolfa Weigla 12, 53-114 Wrocław, Poland toxicity of nanomaterials used in consumer products (Gupta and Xie 2018; Wolfram et al. 2015). The additional source of our concern is the end life of the household products when nanomaterials will be released into the environment. Finally, we are aware of the presence of airborne particulate matter that can have a detrimental effect on health (Riediker et al. 2019).

The definition of nanomaterial is straightforward and says that it is a material that has one of its dimensions below $100 \mathrm{~nm}$ (Naito et al. 2018). Often, this definition is stretched to materials with dimensions above $100 \mathrm{~nm}$, but less than 1 $\mu \mathrm{m}$ or materials that exhibit properties attributable to nanoparticles. For example, and smallest environmental probes PM2.5 are often regarded as nanoparticles (Babadjouni et al. 2018; Gratton et al. 2008). Nevertheless, problems described in this commentary review similarly or even more apply to bigger particles. Wide application of nanotechnology created the great expectations towards the application of nanotechnology in biology and medicine. Despite the large number of studies there are several nanoscale drugs that were 
developed enough to enter clinical studies (Mukhopadhyay 2019). The most promising group are organic nanoparticles, mostly small liposomes or micelles used to increase stability or bio-availability of known drugs (Anselmo and Mitragotri 2019). Such new nanoscale formulations of the well-known drugs can improve the efficacy and selectivity of such medicines. Liposomal formulations of Doxorubicin (Caelyx) or Amphotericin B are leading examples (Cheng et al. 2011; Kopeckova et al. 2019). The other widely studied group of nanoparticles are the inorganic nanomaterials of different chemical composition, surface properties, size, and shapes suited for use in biological systems due to its unique magnetic, luminescent or antibacterial properties. In this regard the iron, lanthanide, gold or silver nanoparticles are most extensively studied (Damasco et al. 2020). Notably, apart from iron nanoparticles, none of the inorganic were approved by responsible regulatory bodies (Bobo et al. 2016; He et al. 2019; Ventola 2017).

At first, most of the nanomaterials, especially made of chemically ambient materials were regarded as non-toxic. Now, with more nanomaterials synthesized and studied we are aware of complex interactions of nanoparticles with living organisms (Lewinski et al. 2008; Saifi et al. 2018; Wysokińska et al. 2016, 2019). Abundance of newly designed nanomaterials calls for cost-effective preliminary assessment of its biological activity and cytotoxicity. In this regard the methods based on in vitro cultures of cells or small organisms are the best option. These are fast, not expensive, easy to scale and do not rise the ethical concerns. The methodology applied in such studies reflects those that is successfully used to test activity and cytotoxicity of soluble drugs or other molecules (De Matteis and Rinaldi 2018; Hillegass et al. 2010; Oliveira et al. 2019). The usual workshop consists of a variety of the cell culturebased techniques, including cytotoxicity studies, assessment of expression of specific proteins and RNA and activity of cell signaling pathway. But unique properties of nanomaterials make the proper selection of conditions for ex vivo testing of its activity or cytotoxicity especially challenging. There is a great literature describing methodology that can be used for in vitro testing of nanoparticles (Azhdarzadeh et al. 2015; De Matteis and Rinaldi 2018; Saifi et al. 2018; Savage et al. 2019). Despite use of well-known methods, there is growing need for further standardization of procedures and methodology in studies regarding nanoparticles. The reason is poor reproducibility of results and difficulties of its comparison (Faria et al. 2018). The guidances are published for researchers and publishers to increase quality of studies and published data. They are indicating possible disturbances of standard procedures that can be introduced by nanomaterials and underline the need for proper description and reporting nanomaterial properties (Faria et al. 2018). But still some aspects important for in vitro testing of nanomaterials are barely discussed and need more attention. This opinion/review will concentrate on the particulate nature of nanoparticles as a unique property of insoluble nanoparticles (or air-derived environmental samples) and its consequences for dosing, testing and exerting in vitro cytotoxic effect. The particulate nature is an obvious and widely unappreciated property of nanoparticles. Especially, in the context of in vitro studies, this property is critical. It should be, but rarely is, considered when designing, performing, describing and interpreting the experiments involving the solid nanoparticles. Here are the main consequences of particulate nature of nanoparticles.

\section{They are Only Billions}

Why we use molar but not weight-based units in chemistry? Mainly, because that the particular molecules interacts with each other. Chemical reactions are stoichiometric and the number of acting chemical species is expressed as moles. Thus, we use molar concentration to describe interactions of chemical compounds with each other. Similarly, in a larger scale, one molecule of inhibitor interacts (usually) with one active site of the enzyme to diminish its activity. The particular number of ligands interacts with the particular number of receptors to trigger a signaling pathway. In end-user applications we alter to mass measure, but mostly for the practical reasons. The nanoparticle is the most basic unit that interact with cells, organelles, cellular structures, receptors, molecules and each other. On the other hand, the nanoscale or micro-scale are not alike a molecular scale. In case of small molecules or ions the number of acting entities extend our imagination $\left(1 \mathrm{~mol}\right.$ as $\left.6.023 \times 10^{23}\right)$. But, in the case of nanoparticles, we usually deal with a large, but limited number of particles. That numbers are smaller than we tend to think about. What numbers it would be? As there is no reliable direct method of counting of nanoparticles, usually we could try to estimate its number by calculations basing on data regarding density and geometry of nanoparticles, light scattering or solution absorbance (Alexander and Goodisman 2014; Austin et al. 2020; Minelli et al. 2018; Park et al. 2004). The density of solid nanomaterials varies from 1 to $20 \mathrm{~g} / \mathrm{cm}^{3}$ (Toy et al. 2011). In case of simple nanomaterials, the density of nanoparticles is closely related with density of original material. In case of complex and new nanomaterials, it can be determined, for example, by volumetric centrifugation method. The geometry of particular nanoparticles can be visualized by electron microscopy. This method along with dynamic light scattering may be used for determination of dimensions of nanoparticles (Eaton et al. 2017). These data can be used for calculations using formulas presented in Table 1 (NanoComposix 2021). To imagine the outstanding divergence between the molecular and nanosized world we 
Table 1 Formulas used for the estimation of volume, mass, molar mass of particles and number of particles in $1 \mu \mathrm{g}$

\begin{tabular}{ll}
\hline volume $_{\text {sphere particle }}=\frac{3}{4} \times \Pi \times\left(\frac{\text { diameter }^{2}}{2}\right)^{3}$ & mass $_{\text {particle }}=$ volume $_{\text {particle }} \times$ density $_{\text {particle }}$ \\
molarmass $_{\text {particle }}=$ mass $_{\text {particle }} \times 6.02214 \times 10^{23}$ & particlenumber $_{(1 \mu \mathrm{g})}=\frac{1 \mu \mathrm{g}}{\text { mass }_{\text {particle }}}$ \\
\hline
\end{tabular}

Table 2 Number of cells cultured in the standard plasticware, as based on the HeLa cell line (Green BioResearch LLC 2016)

\begin{tabular}{llrl}
\hline Type of plasticware & \multirow{2}{*}{$\begin{array}{c}\text { Area } \\
\left(\mathrm{cm}^{2}\right)\end{array}$} & \multicolumn{2}{c}{ Number of cells } \\
\cline { 3 - 4 } & Seeding & $100 \%$ confluent \\
\hline 96-well plate & 0.32 & $10 \times 10^{3}$ & $40 \times 10^{3}$ \\
24-well plate & 1.9 & $30 \times 10^{3}$ & $120 \times 10^{3}$ \\
12-well plate & 3.8 & $100 \times 10^{3}$ & $500 \times 10^{3}$ \\
6-well plate & 9.5 & $300 \times 10^{3}$ & $1.2 \times 10^{6}$ \\
100 mm dish & 57 & $2.2 \times 10^{6}$ & $8.8 \times 10^{3}$ \\
150 mm dish & 145 & $5 \times 10^{6}$ & $20 \times 10^{6}$ \\
\hline
\end{tabular}

could calculate the molar mass of the particular nanoparticles, understand as a mass of $1 \mathrm{~mol}$ of particles (Table 2). In molecular scale the molar mass of are in the range of grams to kilograms (proteins). In nanoscale the molar mass of particles range from kilograms to megatons. It reveals the other property of nanosized world. While molecules differ in weight about few thousand-fold, the weight of nanoparticles varies in million-fold range.

For example, spherical gold nanoparticles have $19.3 \mathrm{~g} /$ $\mathrm{cm}^{3}$ density (Toy et al. 2011). The volume of a single $60 \mathrm{~nm}$ particle is $14.38 \times 10^{-15} \mathrm{~cm}^{3}$. Thus single particle weight
$2.18 \times 10^{-15} \mathrm{~g}$ and there are about $1.31 \times 10^{9}$ (namely billions) of $60 \mathrm{~nm}$ particles in $1 \mu \mathrm{g}$. To compare, the $1 \mu \mathrm{g}$ contains $33.44 \times 10^{15}$ molecules of water, $3.34 \times 10^{15}$ of aspirin, $2.35 \times 10^{15}$ of palmitic acid or finally $103.79 \times 10^{12}$ of insulin (Table 3).

Next, let ask: How such numbers are relevant to in vitro experimental setups? In cell culture studies the effect of nanoparticles on cell viability or metabolism depends primary on the direct interaction with the cells (Sabella et al. 2014; Wysokińska et al. 2016). Thus, the ratio of the nanoparticles and cells will be a relevant factor that affects the likeness of internalization of nanoparticles into the cells. The number of the cells used in in vitro studies vary depending on procedure and cell type. There is usually few to several thousand of adherent cells in a single experimental well. The number of adherent cell in confluent culture varies from 50 thousand to 20-30 millions of HeLa cells (Table 4) (Green BioResearch LLC 2016). When studying the nanoparticles, especially of high density and large we can easily deal with the dose that consist several nanoparticles per cell. Some researchers try to design nanoparticles to be specific to particular molecules or cell structures. We should remember that there is a limited number of such targets in cells. Depending on the type of the target molecules its number

Table 3 The examples of densities of selected nanomaterials along with its number in $1 \mu \mathrm{g}$ and calculated molar mass in comparison to other molecules

\begin{tabular}{|c|c|c|c|c|c|c|}
\hline & $\begin{array}{l}\text { Diameter } \\
(\mathrm{nm})\end{array}$ & $\begin{array}{l}\text { Density } \\
\left(\mathrm{g} / \mathrm{cm}^{3}\right)\end{array}$ & $\begin{array}{l}\text { Weight of single } \\
\text { molecule } \\
(\mathrm{g})\end{array}$ & $\begin{array}{l}\text { Molar mass } \\
(\mathrm{g} / \mathrm{mol})\end{array}$ & Particles per $\mu \mathrm{g}$ & References \\
\hline Water & - & - & $29.91 \times 10^{-24}$ & 18.01 & $33.44 \times 10^{15}$ & \\
\hline Aspirin & - & - & $299.16 \times 10^{-24}$ & 180.16 & $3.34 \times 10^{15}$ & \\
\hline Palmitic acid & - & - & $425.81 \times 10^{-24}$ & 256.43 & $2.35 \times 10^{15}$ & \\
\hline Insulin & - & - & $9.64 \times 10^{-21}$ & $5.808 \times 10^{3}$ & $103.69 \times 10^{12}$ & \\
\hline PBS-loaded liposomes & 65 & 1.0 & $143.79 \times 10^{-18}$ & $86,59 \times 10^{6}$ & $6.95 \times 10^{9}$ & Toy et al. (2011) \\
\hline Iodide-loaded liposomes & 65 & 2.4 & $345.10 \times 10^{-18}$ & $207.83 \times 10^{6}$ & $2.90 \times 10^{9}$ & Toy et al. (2011) \\
\hline Iron oxide nanosphere & 60 & 5.1 & $546.80 \times 10^{-18}$ & $347.36 \times 10^{6}$ & $1.73 \times 10^{9}$ & Toy et al. (2011) \\
\hline $\begin{array}{l}\text { PS } \\
\text { nanosphere }\end{array}$ & 120 & 1.05 & $950.02 \times 10^{-18}$ & $572.36 \times 10^{6}$ & $1.05 \times 10^{9}$ & Minelli et al. (2018) \\
\hline Gold nanosphere & 60 & 19.3 & $2.18 \times 10^{-15}$ & $1.31 \times 10^{9}$ & $458 \times 10^{6}$ & Toy et al. (2011) \\
\hline Silica nanosphere & 2 & 1.11 & $4.65 \times 10^{-21}$ & $2.80 \times 10^{3}$ & $215 \times 10^{12}$ & DeLoid et al. (2014) \\
\hline Silica nanosphere & 20 & 1.11 & $4.65 \times 10^{-18}$ & $2.80 \times 10^{6}$ & $215 \times 10^{9}$ & DeLoid et al. (2014) \\
\hline Silica nanosphere & 200 & 1.11 & $4.65 \times 10^{-15}$ & $2.80 \times 10^{9}$ & $215 \times 10^{6}$ & DeLoid et al. (2014) \\
\hline Iron oxide nanosphere & 2 & 5.1 & $21.36 \times 10^{-21}$ & $12.9 \times 10^{3}$ & $46.8 \times 10^{12}$ & Toy et al. (2011) \\
\hline Iron oxide nanosphere & 20 & 5.1 & $21.36 \times 10^{-18}$ & $12.9 \times 10^{6}$ & $46.8 \times 10^{9}$ & Toy et al. (2011) \\
\hline Iron oxide nanosphere & 200 & 5.1 & $21.36 \times 10^{-15}$ & $12.9 \times 10^{9}$ & $46.8 \times 10^{6}$ & Toy et al. (2011) \\
\hline
\end{tabular}


Table 4 Variations of culture volume/bottom area ratio in different plasticware and volumes that can be used

\begin{tabular}{|c|c|c|c|c|c|c|c|c|c|}
\hline \multirow[t]{2}{*}{ Type of plasticware } & \multirow{2}{*}{$\begin{array}{l}\text { Area } \\
\left(\mathrm{cm}^{2}\right)\end{array}$} & \multicolumn{2}{|c|}{ Total volume } & \multicolumn{2}{|c|}{$\begin{array}{l}1 / 2 \text { of total } \\
\text { volume }\end{array}$} & \multicolumn{2}{|c|}{ Minimal volume } & \multicolumn{2}{|c|}{$\begin{array}{l}\text { Standard } \\
\text { volume }\end{array}$} \\
\hline & & $(\mathrm{ml})$ & $\mathrm{V} / \mathrm{A}$ & $(\mathrm{ml})$ & V/A & $(\mathrm{ml})$ & $\mathrm{V} / \mathrm{A}$ & $(\mathrm{ml})$ & V/A \\
\hline 96-well plate & 0.32 & 0.36 & 1.13 & 0.18 & 0.56 & 0.1 & 0.31 & 0.2 & 0.63 \\
\hline 24-well plate & 1.9 & 3.4 & 1.79 & 1.7 & 0.89 & 0.38 & 0.2 & 1 & 0.53 \\
\hline 12-well plate & 3.8 & 6.9 & 1.82 & 3.45 & 0.91 & 0.76 & 0.2 & 1.5 & 0.39 \\
\hline 6-well plate & 9.5 & 16.8 & 1.77 & 8.4 & 0.88 & 1.9 & 0.2 & 2 & 0.21 \\
\hline
\end{tabular}

This parameter reflects variations of the number of nanoparticles on the bottom when mass/volume concentration is used to describe the dose. Area, total volumes, minimal volumes as indicated by producers of standard plasticware may vary from few thousands to few millions (Biggin 2011). It is estimated that there are about 10 million ribosomes with in the eukaryotic cell or 88,000 of MHC receptors on the fibroblast cell (Boulanger et al. 2018). What effects could we expect if a dose of a few hundreds or even thousands of nanoparticles per cell is applied if ribosomes or MHC molecules are meant to be affected? We could flip the question. Could we exclude the effect of nanoparticles on particular structure if so small dose was used in the studies?

Actually, some studies recognize importance of number, but we should be aware of misreporting. In some studies dose of nanoparticles is expressed in molar concentration, but it regards to amount of original material, not number of nanoparticles (Chithrani et al. 2006). We need to appreciate that number of nanoparticles should be considered in experimental design and result interpretation. The number of acting entities should be related to the number of target cells, organelles, receptors, or molecules. The nanoparticles differ greatly in size and density. Thus, even crude estimations may be good enough to avoid missinterpretations originated from comparing activity of several-fold or hundreds-fold different number of particles. Relation of particle number and target entities should be an important part of interpretation of result.

\section{Many Small Make a Great}

One of the frequent questions asked in toxicology of nanoparticles is the question about impact of size or shape on the cytotoxicity (Gao et al. 2019; Toy et al. 2011; Wysokińska et al. 2016). The question that have very complex answer. Usually, the size/area ratio is indicated as a leading factor. It is correct, but for the whole understanding of nanoparticle activity the relation between the mass and nanoparticle count should also be considered. Attempts to verify the problem of size and shape in direct experiment led us and many researchers to experiment that two or more preparations of similar nanoparticles of different size are compared (Gratton et al. 2008; Wysokińska et al. 2016). The dose is usually defined in mass-related units and the number of particles rarely is regarded as a factor influencing the results. The size of a nanoparticle impacts its number in the mass unit in power of 3 (Table 1, Fig. 1). To illustrate this, if there is $10 \times 10^{9}$ of the $20 \mathrm{~nm}$ nanoparticles in some mass, there would be only $10 \times 10^{6}$ nanoparticles of $200 \mathrm{~nm}$ diameter in the same mass. In the case of spherical gold nanoparticles, there are only about 12 million $200 \mathrm{~nm}$ nanoparticles per $\mu \mathrm{g}$. If we increase the size of the particle to $1 \mu \mathrm{m}$, the number of particles would decrease to about 100 . Sometimes, our knowledge of nanoparticle interaction with biological systems is based on studies where the number of particles differed 140-fold, 300-fold or even 15,000-fold (Borm et al. 2018; Gratton et al. 2008; Mironava et al. 2010).

Similar reasoning should be applied to in vivo experiments. The same mass-related dose of different shapes of nanoparticles was administered. But differences in shape and size resulted in even tenfold difference in number of particles (Perry et al. 2017). How this fact impacts the penetration of tissues by studied compounds?

The other problem often found in studies of nanocompounds is the question about impact of coating on the activity or cytotoxicity of the nanomaterial (Guo et al. 2016; Wysokińska et al. 2016). Usually, the toxic or harsh

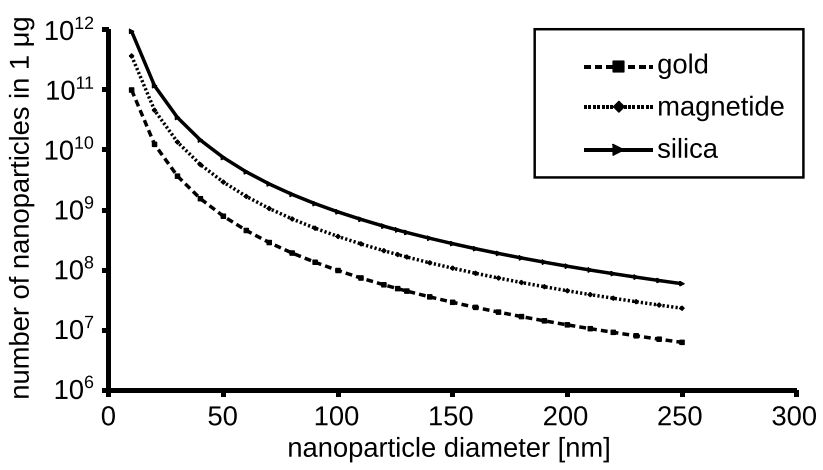

Fig. 1 Size vs. particle number relation for spherical gold $(19.3 \mathrm{~g} /$ $\left.\mathrm{cm}^{3}\right)$, magnetide $\left(5.1 \mathrm{~g} / \mathrm{cm}^{3}\right)$ and silica $\left(1.1 \mathrm{~g} / \mathrm{cm}^{3}\right)$. Particle diameter vs. calculated number in $1 \mu \mathrm{g}$ mass is shown on the graph 
material is coated with ambient material like silica or polyethylene glycol polymer. Let think about spherical $100 \mathrm{~nm}$ material that was coated with $26 \mathrm{~nm}$ layer of silica derivative. And both the core and the coating have the same density. If we perform the experiment and compare weight related doses. Interpreting such an experiment is very challenging. If same weight related dose will be used, then we will compare cytotoxicity of a particular number of bare nanoparticles and half as much number of its coated derivative. Moreover, there is half as much of active/toxic component in mass unit. The second half is the coating (Table 5, Fig. 2). The concluding remark of such studies is that coating reduce toxicity of the nanoparticles (Ishida et al. 2020; Wysokińska et al. 2016). But can we be really convinced that the observed decrease in cytotoxicity is not because there is less toxic component and smaller number of particles in the sample? Should we expect half of dose will be similarly toxic as whole dose?

Table 5 Selected ratios of particle area and number of nanoparticles in arbitrary mass unit

\begin{tabular}{llllll}
\hline Type of nanoparticle & $\begin{array}{l}\text { Mass } \\
(\mathrm{m})\end{array}$ & $\begin{array}{l}\text { Diameter } \\
(\mathrm{nm})\end{array}$ & $\begin{array}{l}\text { Mass of } \\
\text { the core } \\
(\mathrm{m})\end{array}$ & $\begin{array}{l}\text { Num- } \\
\text { ber in } \\
1 \mathrm{~m} \\
(n)\end{array}$ & $\begin{array}{l}\text { Area } \\
(\mathrm{a})\end{array}$ \\
\hline $\begin{array}{c}\text { Spherical core nano- } \\
\text { particle }\end{array}$ & 1 & 100 & 1 & 1 & 1 \\
$\begin{array}{c}\text { Spherical core nano- } \\
\text { particle }\end{array}$ & 2 & 126 & 2 & $1 / 2$ & 1.59 \\
$\begin{array}{c}100 \mathrm{~nm} \text { spherical core } \\
\text { nanoparticle with }\end{array}$ & 2 & 126 & $1 / 2$ & $1 / 2$ & 1.59 \\
26 nm shell & & & & & \\
\hline
\end{tabular}

Relation of mass and number in the bare and coated nanoparticles with assumption of equal densities of shell and core

\section{Truth Lies at the Bottom of a Well}

In majority biological tests, especially in vitro, we test the soluble compounds. The standard procedure is that the tested compound is dispersed in the cell culture media that is later applied to the cell culture. Usually, the nanoparticles are tested in the same way (Azhdarzadeh et al. 2015; Patil et al. 2015; Savage et al. 2019). In that case, silent presumption of solubility or at least homogenic distribution leads us astray. Much guidance does not say anything about distribution of tested nanoparticles. Can we presume the even distribution of nanoparticles in the volume of the experimental well? No, we do not. All the inorganic nanoparticles are insoluble and have higher densities than the cell culture media and sediment on the bottom of the cells (Böhmert et al. 2018). What does it matter to us? It means that the place of interaction of adherent cells and the nanoparticles is defined rather by the area of the cell culture vessel than the volume of culture. Insolubility and sedimentation have further consequences. The dose should not be defined in mass/volume units as by changing the volume of culture, the dose is changed, too.

If in one procedure we apply $1 \mathrm{ml}$ of $100 \mathrm{ng} / \mathrm{ml}$ of nanoparticles to 24-well plate and in the other procedure we add $2 \mathrm{ml}$ of the same nanoparticles in the same $100 \mathrm{ng} /$ $\mathrm{ml}$ concentration, the cells on the bottom will be interacting with twice as many nanoparticles (Table 4). Often, in the same project we study activity of nanoparticles using procedures that call for different scales and thus different plasticware. Switching from 96-well to 6-well dish and preserving mass/volume concentration could result in reduction of dose by three (Table 4). The overwhelming majority of studies regarding inorganic nanoparticles express dose in mass/volume units (Borm et al. 2018; Gnach et al. 2015; Murugadoss et al. 2017; Patil et al. 2015). Thus, without the
Fig. 2 Graphical representation of problem of design and interpretation experiment with bare and and coated nanoparticles. If mass-related dose is used and coating increase size of particle then unequal number of particle is used and only portion of core material added to the experimental system. If $13 \mathrm{~nm}$ thick coating is applied on $100 \mathrm{~nm}$ nanoparticle then number of particles is reduced by half

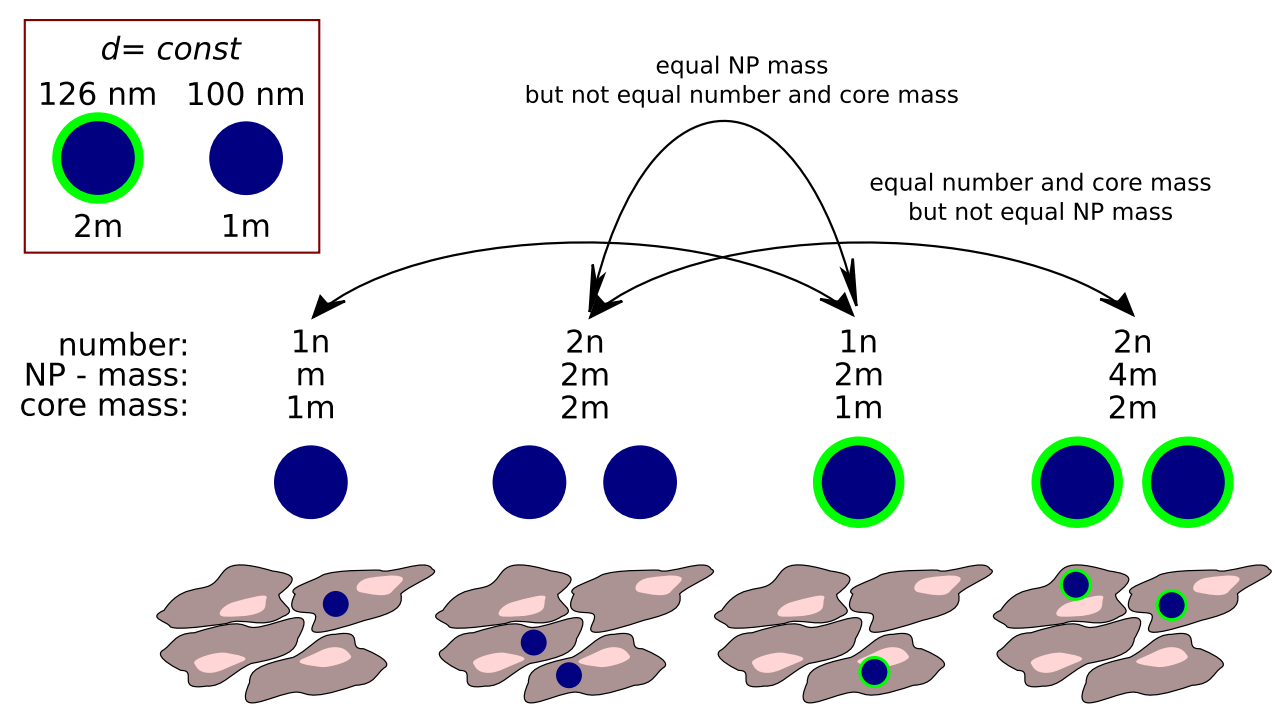


detailed information about cell culture conditions like plastic type (area) and volumes the dose remains unknown and thus incomparable throughout the different studies. To make this matter even more complex. We really can not presume that all particle sediment on the bottom of the plate. In the case of $80 \mathrm{~nm}$ gold nanoparticles it can take as much as $120 \mathrm{~h}$ to sediment on the bottom (Alexander and Goodisman 2014). Moreover, some studies show that it takes about a week to deliver a full applied dose of $15 \mathrm{~nm}$ gold particles to the Caco- 2 cells (Böhmert et al. 2018). But still, substantial part of the dose sediment in the first few hours (Böhmert et al. 2018). The sedimentation process can be modeled using effective density of NP, medium density and viscosity, and other parameters. But in that time cells should not be handled that is impractical in most procedures. Second, we can not presume that the mono-layer cells grow exclusively on the bottom of the well, some cells were shown to grow on the walls (Böhmert et al. 2018). The portion of such cell could be neglected in case of large culture plates or flasks, but in case of often used 96-well plate such cells can account for even 50\% of cells (Böhmert et al. 2018).

The matter is even more complicated in case of nonadherent cell cultures. Cells and nano-compounds sediment with in different rate. In that case, defining the place of interaction and modeling of interaction of nanoparticles with suspension cell culture is even more difficult. In general, sedimentation is a huge problem. Most of the publications regarding nanoparticles use the mass/volume concentration as the measure of dose. The authors rarely include information about plastic-ware type and volumes used for the treatments. Without such information it is impossible to estimate the actual dose applied to the cells and thus compare the results and draw meaningful conclusions.

\section{Conclusions}

The problem is clear, but the solutions are hazed. The first conclusion is that we should count nanoparticles. But we should ask a practical question. Can we count the nanoparticles? Even commercially available nanoparticles are not always counted and shipped with proper information. The existing calculators base on density and shape of nanoparticles for calculation of its number (NanopartZ 2021). But measurement of the density of newly developed material is also not standard procedure. The size of nanoparticles in the sample often vary, so we should be aware that our results are rather estimations than calculations (Schavkan et al. 2019). Nevertheless, the estimations should be made, and the aspect of actual number of particles studied should be present in experimental design and interpretation of results. In some experimental design, like coating studies the number of particles can be more important than mass or area of nanoparticles. Even crude estimation will be extremely useful for proper interpretation of results. The additional controls, consisting same number of particles should be included in studies. Second, we can not express the dose of insoluble nanoparticles in mass/volume units, especially in the studies performed on cells grown in mono-layer. By itself it says nothing. If we express the dose as mass $/ \mathrm{cm}^{2}$ we will avoid variability of results that come from different cell culture conditions. If we want to compare the activity of different nanoparticles the number/area units seem to be the best option to express the dose. On the other hand, when the particle is soluble within the cell, the overall mass of the nanomaterial will be also important factor. Thus a good practice of reporting is vital (Faria et al. 2018). Moreover, we need to keep in mind that this is merely compromise that omit the time of sedimentation, cells growing on the walls or spontaneous aggregation (DeLoid et al. 2014). To overcome sedimentation process we could think about gentle spinning cells at beginning of procedure as it is done during some transfection protocols, but we need to be aware that such manipulation may additionally facilitate interaction of cells and nanoparticles.

Third, we as biologist need to be aware of the unique nature of material that our colleague chemist gave us for testing because our habits and standards may lead us astray. There is no such thing as a simple cytotoxicity test. The most important conclusion is that we should be always aware of the corpuscular nature of nanoparticles. The consequence that is its limited number of nanoparticles in the sample. Estimations of number of nanoparticles in the dose should be an integral part of experiment design and always should be included in interpretation of results, especially when comparing different sized and shaped nanoparticles.

Funding This work was supported by Hirszfeld Institute of Immunology and Experimental Therapy research program 3/2021.

\section{Declarations}

Conflict of interest The author have no conflicts of interest to declare that are relevant to the content of this article.

Open Access This article is licensed under a Creative Commons Attribution 4.0 International License, which permits use, sharing, adaptation, distribution and reproduction in any medium or format, as long as you give appropriate credit to the original author(s) and the source, provide a link to the Creative Commons licence, and indicate if changes were made. The images or other third party material in this article are included in the article's Creative Commons licence, unless indicated otherwise in a credit line to the material. If material is not included in the article's Creative Commons licence and your intended use is not permitted by statutory regulation or exceeds the permitted use, you will need to obtain permission directly from the copyright holder. To view a copy of this licence, visit http://creativecommons.org/licenses/by/4.0/. 


\section{References}

Alexander CM, Goodisman J (2014) Size histograms of gold nanoparticles measured by gravitational sedimentation. J Colloid Interface Sci 418:103-112. https://doi.org/10.1016/j.jcis.2013.11.074

Anselmo AC, Mitragotri S (2019) Nanoparticles in the clinic: an update. Bioeng Transl Med 4:e10143. https://doi.org/10.1002/ btm2.10143

Austin J, Minelli C, Hamilton D et al (2020) Nanoparticle number concentration measurements by multi-angle dynamic light scattering. J Nanoparticle Res 22:108. https://doi.org/10.1007/ s11051-020-04840-8

Azhdarzadeh M, Saei AA, Sharifi S et al (2015) Nanotoxicology: advances and pitfalls in research methodology. Nanomedicine 10:2931-2952. https://doi.org/10.2217/nnm.15.130

Babadjouni R, Patel A, Liu Q et al (2018) Nanoparticulate matter exposure results in neuroinflammatory changes in the corpus callosum. PLoS ONE 13:e0206934. https://doi.org/10.1371/journal.pone. 0206934

Biggin MD (2011) Animal transcription networks as highly connected, quantitative continua. Dev Cell 21:611-626. https://doi.org/10. 1016/j.devcel.2011.09.008

Bobo D, Robinson KJ, Islam J et al (2016) Nanoparticle-based medicines: a review of FDA-approved materials and clinical trials to date. Pharm Res 33:2373-2387. https://doi.org/10.1007/ s11095-016-1958-5

Böhmert L, König L, Sieg H et al (2018) In vitro nanoparticle dosimetry for adherent growing cell monolayers covering bottom and lateral walls. Part Fibre Toxicol 15:42. https://doi.org/10.1186/ s12989-018-0278-9

Borm PJA, Fowler P, Kirkland D (2018) An updated review of the genotoxicity of respirable crystalline silica. Part Fibre Toxicol 15:23. https://doi.org/10.1186/s12989-018-0259-z

Boulanger DSM, Eccleston RC, Phillips A et al (2018) A mechanistic model for predicting cell surface presentation of competing peptides by MHC class I molecules. Front Immunol 9:1538. https:// doi.org/10.3389/fimmu.2018.01538

Cheng L, Yang K, Shao M et al (2011) In vivo pharmacokinetics, long-term biodistribution and toxicology study of functionalized upconversion nanoparticles in mice. Nanomedicine 6:1327-1340. https://doi.org/10.2217/nnm.11.56

Chithrani BD, Ghazani AA, Chan WCW (2006) Determining the size and shape dependence of gold nanoparticle uptake into mammalian cells. Nano Lett 6:662-668. https://doi.org/10.1021/n1052 3960

Damasco JA, Ravi S, Perez JD et al (2020) Understanding nanoparticle toxicity to direct a safe-by-design approach in cancer nanomedicine. Nanomaterials 10:2186. https://doi.org/10.3390/nano1 0112186

De Matteis V, Rinaldi R (2018) Toxicity assessment in the nanoparticle era. In: Saquib Q, Faisal M, Al-Khedhairy AA, Alatar AA (eds) Cellular and molecular toxicology of nanoparticles. Springer, Cham, pp 1-19

DeLoid G, Cohen JM, Darrah T et al (2014) Estimating the effective density of engineered nanomaterials for in vitro dosimetry. Nat Commun 5:3514. https://doi.org/10.1038/ncomms4514

Eaton P, Quaresma P, Soares C et al (2017) A direct comparison of experimental methods to measure dimensions of synthetic nanoparticles. Ultramicroscopy 182:179-190. https://doi.org/10. 1016/j.ultramic.2017.07.001

Faria M, Björnmalm M, Thurecht KJ et al (2018) Minimum information reporting in bio-nano experimental literature. Nat Nanotechnol 13:777-785. https://doi.org/10.1038/s41565-018-0246-4
Gao W, Wang Y, Xiong Y et al (2019) Size-dependent anti-inflammatory activity of a peptide-gold nanoparticle hybrid in vitro and in a mouse model of acute lung injury. Acta Biomater 85:203-217. https://doi.org/10.1016/j.actbio.2018.12.046

Gnach A, Lipinski T, Bednarkiewicz A et al (2015) Upconverting nanoparticles: assessing the toxicity. Chem Soc Rev 44:1561-1584. https://doi.org/10.1039/C4CS00177J

Gratton SEA, Ropp PA, Pohlhaus PD et al (2008) The effect of particle design on cellular internalization pathways. Proc Natl Acad Sci USA 105:11613-11618. https://doi.org/10.1073/pnas.0801763105

Green BioResearch LLC (2016) Cell density number at $100 \%$ confluency in cell culture dish, plate, flask. https://greenbioresearch. $\mathrm{com} /$ cell-number-density-percentage-confluency-cell-culturedish-plate-flask/. Accessed 27 May 2021

Guo X, Li Y, Yan J et al (2016) Size- and coating-dependent cytotoxicity and genotoxicity of silver nanoparticles evaluated using in vitro standard assays. Nanotoxicology 10:1373-1384. https:// doi.org/10.1080/17435390.2016.1214764

Gupta R, Xie H (2018) Nanoparticles in daily life: applications, toxicity and regulations. J Environ Pathol Toxicol Oncol 37:209-230. https://doi.org/10.1615/JEnvironPatholToxicolOncol.2018026009

He H, Liu L, Morin EE et al (2019) Survey of clinical translation of cancer nanomedicines-lessons learned from successes and failures. Acc Chem Res 52:2445-2461. https://doi.org/10.1021/acs. accounts.9b00228

Hillegass JM, Shukla A, Lathrop SA et al (2010) Assessing nanotoxicity in cells in vitro. Wiley Interdiscip Rev Nanomed Nanobiotechnol 2:219-231. https://doi.org/10.1002/wnan.54

Hobson DW, Roberts SM, Shvedova AA et al (2016) Applied nanotoxicology. Int J Toxicol 35:5-16. https://doi.org/10.1177/10915 81816628484

Ishida N, Hosokawa Y, Imaeda T et al (2020) Reduction of the cytotoxicity of copper (II) oxide nanoparticles by coating with a surfacebinding peptide. Appl Biochem Biotechnol 190:645-659. https:// doi.org/10.1007/s12010-019-03108-9

Kopeckova K, Eckschlager T, Sirc J et al (2019) Nanodrugs used in cancer therapy. Biomed Pap Med Fac Univ Palacky Olomouc Czech Repub 163:122-131. https://doi.org/10.5507/bp.2019.010

Lewinski N, Colvin V, Drezek R (2008) Cytotoxicity of nanoparticles. Small 4:26-49. https://doi.org/10.1002/smll.200700595

Minelli C, Sikora A, Garcia-Diez R et al (2018) Measuring the size and density of nanoparticles by centrifugal sedimentation and flotation. Anal Methods 10:1725-1732. https://doi.org/10.1039/ C8AY00237A

Mironava T, Hadjiargyrou M, Simon M et al (2010) Gold nanoparticles cellular toxicity and recovery: effect of size, concentration and exposure time. Nanotoxicology 4:120-137. https://doi.org/ $10.3109 / 17435390903471463$

Mukhopadhyay S (2019) Nano drugs. In: Mohapatra S, Ranjan S, Dasgupta $\mathrm{N}$ (eds) Characterization and biology of nanomaterials for drug delivery. Elsevier, Amsterdam, pp 523-551

Murugadoss S, Lison D, Godderis L et al (2017) Toxicology of silica nanoparticles: an update. Arch Toxicol 91:2967-3010. https://doi. org/10.1007/s00204-017-1993-y

Naito M, Yokoyama T, Hosokawa K et al (2018) Chapter 1-basic properties and measuring methods of nanoparticles. Nanoparticle technology handbook, 3rd edn. Elsevier, Amsterdam, pp 3-47

nanoComposix (2021) Nanoparticle volume, mass and concentration-nanoComposix. https://nanocomposix.com/pages/nanop article-volume-mass-and-concentration. Accessed 11 Jun 2021

NanopartZ (2021) Gold nanoparticle conversion tools-optical and physical properties. https://www.nanopartz.com/conversion_tools. asp. Accessed 11 Jun 2021

Oliveira H, Bednarkiewicz A, Falk A et al (2019) Critical considerations on the clinical translation of upconversion nanoparticles 
(UCNPs): Recommendations from the European Upconversion Network (COST Action CM1403). Adv Healthc Mater 8:e1801233. https://doi.org/10.1002/adhm.201801233

Park K, Kittelson DB, Zachariah MR et al (2004) Measurement of inherent material density of nanoparticle agglomerates. J Nanoparticle Res 6:267-272. https://doi.org/10.1023/B:NANO.00000 34657.71309.e6

Patil US, Adireddy S, Jaiswal A et al (2015) In vitro/in vivo toxicity evaluation and quantification of iron oxide nanoparticles. Int $\mathrm{J}$ Mol Sci 16:24417-24450. https://doi.org/10.3390/ijms161024417

Perry JL, Reuter KG, Luft JC et al (2017) Mediating passive tumor accumulation through particle size, tumor type, and location. Nano Lett 17:2879-2886. https://doi.org/10.1021/acs.nanolett. $7 \mathrm{~b} 00021$

Riediker M, Zink D, Kreyling W et al (2019) Particle toxicology and health-where are we? Part Fibre Toxicol 16:19. https://doi.org/ 10.1186/s12989-019-0302-8

Sabella S, Carney RP, Brunetti V et al (2014) A general mechanism for intracellular toxicity of metal-containing nanoparticles. Nanoscale 6:7052-7061. https://doi.org/10.1039/c4nr01234h

Saifi MA, Khan W, Godugu C (2018) Cytotoxicity of nanomaterials: using nanotoxicology to address the safety concerns of nanoparticles. Pharm Nanotechnol 6:3-16. https://doi.org/10.2174/22117 38505666171023152928

Savage DT, Hilt JZ, Dziubla TD (2019) In vitro methods for assessing nanoparticle toxicity. Methods Mol Biol 1894:1-29. https://doi. org/10.1007/978-1-4939-8916-4_1
Schavkan A, Gollwitzer C, Garcia-Diez R et al (2019) Number concentration of gold nanoparticles in suspension: SAXS and spICPMS as traceable methods compared to laboratory methods. Nanomaterials 9:502. https://doi.org/10.3390/nano9040502

Toy R, Hayden E, Shoup C et al (2011) Effect of particle size, density and shape on margination of nanoparticles in microcirculation. Nanotechnology 22:115101. https://doi.org/10.1088/0957-4484/ 22/11/115101

Ventola CL (2017) Progress in nanomedicine: approved and investigational nanodrugs. Pharm Ther 42:742-755

Wolfram J, Zhu M, Yang Y et al (2015) Safety of nanoparticles in medicine. Curr Drug Targets 16:1671-1681. https://doi.org/10. 2174/1389450115666140804124808

Wysokińska E, Cichos J, Zioło E et al (2016) Cytotoxic interactions of bare and coated NaGdF4: $\mathrm{Yb}(3+): \operatorname{Er}(3+)$ nanoparticles with macrophage and fibroblast cells. Toxicol Vitro 32:16-25. https:// doi.org/10.1016/j.tiv.2015.11.021

Wysokińska E, Cichos J, Kowalczyk A et al (2019) Toxicity mechanism of low doses of NaGdF4:Yb3+, Er3+ upconverting nanoparticles in activated macrophage cell lines. Biomolecules 9:14. https://doi.org/10.3390/biom9010014

Publisher's Note Springer Nature remains neutral with regard to jurisdictional claims in published maps and institutional affiliations. 